\title{
James Spence Medallist, 1981
}

\author{
Elsie May Widdowson
}

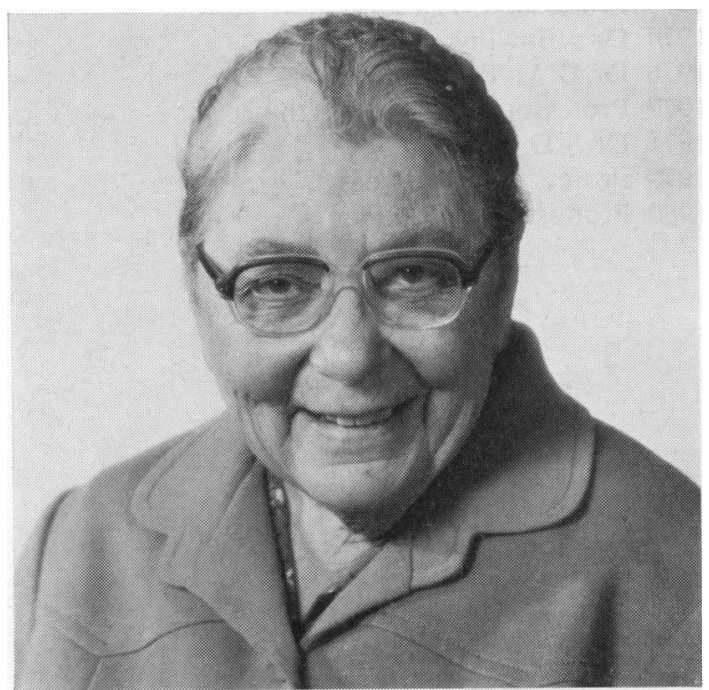

Elsie Widdowson joined the scientific staff of the Medical Research Council in 1933 and remained in their service until her retirement in 1973. She worked for most of these years with Professor R A McCance, first in the Biochemical Department at King's College Hospital, London, and from 1938 in the Department of Experimental Medicine in Cambridge where she was assistant head of the department from 1952 to 1966. From 1966 to 1973 she was head of the Medical Research Council Infant Nutrition Research Division at the Dunn Nutritional Laboratory and since her retirement has received a Medical Research Council research grant and is still working at the Department of Medicine, Addenbrooke's Hospital, Cambridge. Much of Dr Widdowson's work has been concerned with nutrition, in its broadest sense-the composition of foods, mineral metabolism, the chemical composition of the body, undernutrition in man and experimental animals, and more recently, with growth and the nutritional requirements of the fetus and newly born. Dr Widdowson was elected a Fellow of the Royal Society in 1976 and was awarded a CBE in 1979. The University of Manchester conferred on her an honorary DSc in 1974. She is immediate past President of the Neonatal Society and the Nutrition
Society. She is a member of many scientific committees, including several at the Department of Health; her publications number more than 300 .

At the annual meeting of the British Paediatric Association in York on 10 May the President, Dr G K Komrower, reviewed her career and stressed how

'she portrays so many of the attributes James Spence admired: clear and original thinking, wholehearted involvement in the task under consideration, and research with a practical application. In addition her warm and kindly nature has encouraged one British professor of medicine to declare "We love her very dearly and respect her as few other colleagues".'

Dr Komrower stressed the great importance of her influence on nutritional research,

'She is the authority on the composition of foods. Working with Dagmar Wilson on vitamin D metabolism they substantiated the observation that women and children deprived of vitamin $\mathrm{D}$ and low in calcium did not develop rickets or osteomalacia if they exposed their bodies to the sun compared with the communities who remained indoors. In the postwar years bread and milk were open to research and she answered the questions "Is white flour enriched with iron and B vitamins as good as high extraction flour?" "What is the effect of nutrition on the volume and composition of breast milk?" (This work was in collaboration with Mavis Gunther and Jean Stanier).

'Her contributions to paediatrics, both in this country and overseas, have been considerable and have led her admirers to say that she knows more about the growth and development of babies than any paediatrician. Be that as it may, paediatrics has been very fortunate in having such a good, well-informed, and scientifically inquisitive friend who has been so willing to help us with our specific problems. When Elsie Widdowson made her presidential address to the Nutrition Society she concluded with these words "If I were asked what has been most important to me in all my adventures in nutrition over half a century I would say without hesitation it has been the companionship of my 
partner Professor McCance. He has taught me, inspired me, supported and helped me all the way along." Therefore I shall now ask Professor R A McCance (who himself was awarded the James Spence Medal 20 years ago) to present the James Spence Medal for 1981 to Dr Elsie Widdowson on our behalf.'

\section{James Spence Medallists}

1960 Professor A A Moncrieff

1961 Professor R A McCance

1963 Sir F Macfarlane Burnet

1964 Professor L S Penrose
1965 Dr Cicely D Williams

1967 Professor R R A Coombs

1968 Dr Mary D Sheridan Dr D W Winnicott

1969 Dr G S Dawes

1970 Professor D V Hubble

1971 Dr W W Payne

1972 Dr R C Mac Keith

1973 Professor C A Clarke

1974 Dr J Bowlby

1976 Dr D M T Gairdner

1977 Professor R S Illingworth

1978 Dr S D M Court

1979 Professor K W Cross

1980 Professor J M Tanner 